\title{
Behavioral and developmental homeostasis in the fire ant, Solenopsis invicta
}

\author{
Deby Lee Cassill *, Walter R. Tschinkel \\ Department of Biological Science, Florida State University, Tallahassee, FL 32306-3050, USA
}

Received 28 May 1999; accepted 5 October 1999

\begin{abstract}
The von Bertalanffy rule (1960) predicts that low incubation temperature during larval development will result in larger adult body size. If larval development in social insects followed this rule, then low incubation temperature would induce the development of larger workers and possibly even sexuals. To test this prediction, the effect of incubation temperature on larval development, larval meal size, larval tending and worker recruitment to food in the fire ant, Solenopsis invicta was investigated. Temperatures tested where within the range at which brood remains viable.

Contrary to the predictions of the von Bertalanffy rule, worker size was unaffected by incubation temperature, and sexuals were reared at the high rather than the low incubation temperature. Moreover, larval meal size, the rate of larval tending by workers and the total number of workers recruited to food were unaffected by temperature.

Mechanisms regulating developmental and behavioral homeostasis were as follows: the duration of larval development and the rate of larval growth changed proportionately with temperature such that the mean and variation of pupal size was unaffected by incubation temperature. Larvae solicited at the same rate, swallowed at the same rate and swallowed for the same duration such that meal size was unaffected by incubation temperature. On the brood pile, fewer workers tended brood at higher incubation temperatures, but worker tempo increased; as a result, brood tending was not adversely affected by incubation temperature. The rate of worker recruitment to food sites outside the nest increased with temperature, but the duration of the recruitment effort decreased such that, over time, the same total number of workers was employed to retrieve food.

Incubation humidity was also investigated. When brood chambers were less than $100 \%$ humid, workers recruited to food and tended larvae (retrieved, sorted and groomed them), but did not feed larvae. Eventually, larvae died of starvation and were cannibalized. () 2000 Elsevier Science Ltd. All rights reserved.
\end{abstract}

Keywords: Compensatory behavior; Caste determination; Nest; Feeding; Trophallaxis; Worker polyphenism; Formicidae

\section{Introduction}

Insects are ectotherms, thus their rate of growth, time to maturity and final adult size may depend upon the temperature of their rearing environment as well as their diet (Slansky and Scriber, 1985; Atkinson, 1994; Atkinson and Sibly, 1997). The inverse relationship between body size and developmental temperature, the von Bertalanffy rule (von Bertalanffy, 1960), has been found in many species of solitary insects (Hogue and Hawkins,

\footnotetext{
* Corresponding author. Tel.: +1-520-621-1151 fax: +1-520-6211150 .

E-mail address: dcassill@ag.arizona.edu (D.L. Cassill).
}

1991; Gu and Danthanarayana, 1992; Bouletreau-Merle and Sillans, 1996; Arnett and Gotelli, 1999).

The relationship between body size and incubation temperature for social insects is less well studied. In the termite, Coptotermes formosanus, low incubation temperature produced smaller nymphs (Waller and La Fage, 1988). In the sweat bee, Halictus ligatus, cool rainy weather during the breeding season produced smaller body size in workers and alates than warm, dry weather (Richards and Packer, 1996). In the ant genus Myrmica, the temperature at which eggs are laid determines whether larvae develop rapidly and become workers or whether they hibernate and retain the potential to become queens (Brian, 1955, 1956, 1963). Hibernating queen-biased larvae are more likely to succeed in becoming queens when incubated at an intermediate 
temperature than at a low or high temperature (Brian, 1973). However, the final size of worker-biased larvae reared early in the breeding season was unaffected by incubation temperature (Elmes and Wardlaw, 1983). Thus, worker size was independent of incubation temperature within the viable range, but adult caste was not.

The fire ant, Solenopsis invicta, is a perennial species subjected, not only to diurnal temperature fluctuations, but also to seasonal fluctuations. Nesting in the soil buffers these ants from air temperature extremes. In addition, the deep and complex nests built by fire ants (Tschinkel, 1998) provide the queen and workers a choice of incubation conditions in which to lay eggs and to rear larvae. Workers move brood up and down temperature and moisture gradients several times a day to optimize incubation conditions (Potts et al., 1984; Porter and Tschinkel, 1993). The incubation temperature for optimal brood development in this species is $32^{\circ} \mathrm{C}$ with a survival range of $25-35^{\circ} \mathrm{C}$ (Porter, 1988). Because thousands of larvae and pupae are distributed among thousands of small brood chambers at any given time (Cassill, 1996), many may experience less than optimal incubation conditions.

If worker body size follows the von Bertalanffy rule (1960), variation in incubation temperature induced by nest complexity could explain the observed variation in worker body size within a cohort (Tschinkel, 1988). Moreover, temperature could regulate a beneficial tradeoff between colony size and worker body size. The observed increase in colony size at higher temperatures (Porter, 1988; Porter and Tschinkel, 1993) might be mediated by the production of smaller workers (Porter and Tschinkel, 1986).

Temperature could regulate individual growth and development directly via a temperature switch (Brian, 1956), indirectly via a nutritional switch (Wheeler, 1986) or both (Passera, 1974). If polyphenism was regulated directly by a temperature switch, cool incubation temperature could induce a rise in $\mathrm{JH}$ levels, initiating major or gyne development. Subsequently, the rate of larval growth would increase causing larvae to signal more often for feedings (Cassill and Tschinkel, 1995, 1999a). Alternatively, temperature-delayed development could result in a larger number of meals for a larva such that, when nutrition was sufficient, JH levels could rise, initiating major or gyne development. In this paper, we report the effects of incubation temperature on larval development, larval meal size, worker brood tending and worker recruitment to food. In addition, we report the effects of incubation humidity on these same variables.

\section{Materials and methods}

\subsection{Source colonies}

For temperature experiments, mature field colonies were collected in Tallahassee during January of 1995 and maintained at $28^{\circ} \mathrm{C}$ in constant light for one month. Colonies were fed a diet of tenebrionid beetle larvae and $20 \%$ sugar water. For the humidity experiment, year-old laboratory-reared colonies were used. These colonies were reared from newly-mated, monogyne, Solenopsis invicta queens collected in Tallahassee, Florida, U.S.A. during the spring of 1989. Both colony types were maintained by methods similar to those described by Banks et al. (1981). There is no difference in the rates of feeding between laboratory-reared and field-reared larvae (Cassill and Tschinkel, 1999b).

\subsection{Larval development}

To examine the effect of temperature on final adult caste or size, larvae from eight source colonies were combined, sifted to collect small 4th instar larvae (mesh \#35; Cassill and Tschinkel, 1995) and divided into groups of $0.1 \mathrm{~g}$ each ( $\sim 100$ individuals). Each larval group was placed into an experimental nest containing 100 workers. The size of experimental colony fragments were comparable to the size of groups found in subterranean brood chambers in the field (Cassill, 1996). The final number of brood successfully reared was not determined.

Experimental brood chambers were circular with a diameter of $2.25 \mathrm{~cm}$ and a depth of $0.3 \mathrm{~cm}$, comparable to the mean size of subterranean chambers in the field. Two colony fragments were established from a source colony. One of the pair was incubated at $25^{\circ} \mathrm{C}$, the lowest temperature at which brood can be successfully reared. The other was incubated at $32^{\circ} \mathrm{C}$, the temperature at which optimal colony growth occurs (Porter and Tschinkel, 1993). Both were fed $20 \%$ sugar water, water and thawed tenebrionid larvae ad libitum. Each week for a total of three weeks, a random sample of 20 white pupae (a surrogate for adult size, Porter and Tschinkel, 1985) was harvested from each fragment $(n=16 \times 3)$. Pupae were sampled during the time when both groups were producing abundant pupae. Pupae were weighed individually. Pupae with a mass between $1 \mathrm{mg}$ and 4.25 mg were counted as majors; those with a mass $<1 \mathrm{mg}$ were counted as minors. These procedures were replicated using four different source colonies.

\subsection{Larval meal size}

Larval appetites were quantified using video technology (see Cassill and Tschinkel, 1995, 1999a). Food for larval feeding consisted of a distilled water solution with $6 \%(\mathrm{w} / \mathrm{v})$ casamino acids powder and $10 \%$ granulated sugar $(\mathrm{w} / \mathrm{v})$. We tested temperatures within the range of viable brood production $-25^{\circ} \mathrm{C}, 30^{\circ} \mathrm{C}$ and $35^{\circ} \mathrm{C}$. From one source colony, $8 \mathrm{~g}$ of workers were divided into three groups of $2 \mathrm{~g}$ each. Each group was placed into an experimental nest and deprived of food 
for $48 \mathrm{~h}$. Larvae were collected using the same methods as reported above, then placed temporarily into a single brood chamber and deprived of food for $12 \mathrm{~h}$. Nests containing workers were placed in the temperature-controlled room to acclimate $12 \mathrm{~h}$ before the experiment began. One gram of larvae was added to each experimental nest $2 \mathrm{~h}$ before the experiment began. Fire ants respond within seconds to the immediate temperature, regardless of the historic temperature (Potts et al., 1984). Food was introduced $30 \mathrm{~min}$. before videotaping began. Taping lasted $2 \mathrm{~h}$. These procedures were replicated using a total of four source colonies.

A portion of this experiment was repeated using three additional source colonies tested at $25^{\circ} \mathrm{C}$ and $35^{\circ} \mathrm{C}$. This time, starved larvae were placed in the nest with workers $12 \mathrm{~h}$, instead of $2 \mathrm{~h}$, before food introduction and videotaping. Temperature probes (VIS Tele-Thermometer; YSI 400 series) were placed inside the brood chambers to confirm that ants were indeed experiencing those temperatures established by the experimental protocol. In addition, a thermometer was placed vertically on the wall just above the nest and another horizontally on the table beside the nest. Temperatures did not vary more than $0.5^{\circ} \mathrm{C}$ among thermometers nor did the temperature vary more than $1.0^{\circ} \mathrm{C}$ during the experiment. Results on larval feeding from the second experiment did not differ significantly from the first experiment; therefore, data were pooled for analysis.

\subsection{Worker brood tending}

A grid with $5 \times 5 \mathrm{~cm}$ cells was drawn on the monitor with a black marker. After pausing the videotape, the cells containing larvae $(N)$ were counted as were the cells containing both larvae and workers $(n)$. A cell was considered to contain a worker if at least half of a worker's body was within the $25 \mathrm{~cm}^{2}$ cell. The percent of brood pile coverage was calculated as $n / N \times 100$. The videotape was paused three times randomly for each treatment in each replicate $(n=36)$. The rate at which workers encountered larvae was determined by counting the number of workers that antennated a larva per hour.

\subsection{Worker recruitment}

For the replicates in which larval feeding was compared at $25^{\circ} \mathrm{C}$ and $35^{\circ} \mathrm{C}$, the number of workers recruited to the food site was counted after food placement in the arena at $10 \mathrm{~min}$ and again at $60 \mathrm{~min}$. Three replicates were completed.

\subsection{Humidity}

The effect of nest moisture on larval appetite was tested on laboratory-reared colonies under two incubation conditions, dry (50-65\% ambient humidity) or moist nest chambers (100\% humidity). A colony was starved for $48 \mathrm{~h}$, then $2 \mathrm{~g}$ of workers $(\sim 4,000)$ were randomly aspirated from the brood chamber and foraging arena. Worker groups were halved and each half $(1 \mathrm{~g})$ was placed into either a dry brood chamber or a watersaturated chamber. Next, $1.0 \mathrm{~g}$ of larvae were aspirated from the source colony's brood chamber, divided into half and each half $(\sim 1,000)$ was placed in each of two experimental nests. Dyed food (Cassill and Tschinkel, 1995) was introduced into the arena of each experimental nest. After $1 \mathrm{~h}$, the number of fed larvae, as evidenced by the presence of dyed food in the mid-gut, was counted. Approximately 200 larvae were sampled per nest (50 each from four different locations on the brood pile). Colony fragments were maintained for three weeks on a standard diet (see Methods) to determine the fate of larvae in dry nests. Replicates from 10 laboratoryreared source colonies were completed.

\subsection{Data analysis}

Dependent variables included: rate of worker-to-larva trophallaxis (number/larva/h); duration of trophallaxis (s); rate of larval swallowing (number of boluses/s); duration of larval swallowing (s); lapsed time to first feeding (s); worker density on brood pile (percent of brood pile occupied by workers); rate at which workers encountered a larva (number/h); number of workers recruited to food site; percent of larvae fed; and pupal weight (mg). Depending upon the experiment, data were analyzed using ANOVA or ANCOVA with larval size as a covariate. ANOVA differences were reported as significant at $P<0.05$. To determine differences among cell means, Tukey's Honestly Significant Difference test was used. Diagnostic analysis was routinely performed to check for outliers (S.D. > 2.90) and to determine if assumptions of normality and uniform variance held. Data did not require transformation.

\section{Results}

\subsection{Larval development}

No significant difference in mean worker size was found between incubation temperatures $(P=0.385)$ or among dates $(P=0.715)$. There was a significant difference in mean worker size among colonies $(P<0.001)$ with one colony producing larger workers on average than the other three colonies. Interactions among temperature, colony and date were not significant. There was no effect of temperature on variance in worker size (COV: $\mathrm{X}_{0.05,1}^{2}=0.148 ; P=$ n.s.) nor on worker size within subcaste (major subcaste: $P=0.565$; minor subcaste: $P=0.469$ ). Temperature had no effect on the ratio of 
major/minor workers (nonparametric: $P=0.118$ ) or on the number of majors produced $\left(\mathrm{X}^{2}=3.0, P=0.083\right)$.

A handful of sexual pupae was produced by each of the colony fragments incubated at $32^{\circ} \mathrm{C}$ (mean $=6$ per colony fragment). Sexual pupae were a mixture of males and gynes. No sexuals were produced in colony fragments incubated at $25^{\circ} \mathrm{C}$.

\subsection{Larval meal size}

There was no difference in the rate of worker-to-larva regurgitation among temperatures $(P=0.252)$. Mean rate of regurgitation was $25.0 \mathrm{~h}^{-1} \pm 6$ S.D.; minimum $=5 \mathrm{~h}^{-1}$; maximum $=35 \mathrm{~h}^{-1}$. There was no effect of temperature on the lapsed time to the first feeding per larva $(P=0.544)$. Mean lapsed time to the first feeding was $4.0 \pm 0.9$ min S.D.; minimum $=0.5 \mathrm{~min}$; maximum $=14.2$ min. However, the mean duration of regurgitation was inversely proportional to temperature $(P<0.001)$, doubling from $11 \mathrm{~s}$ at $35^{\circ} \mathrm{C}$ to $23 \mathrm{~s}$ at $25^{\circ} \mathrm{C}$.

Because low temperature extended the duration of regurgitation, larvae might have been receiving larger meals. Therefore, the rate and duration of larval swallowing was investigated using a dissecting microscope at $\times 80$ magnification and fiber-optic lights. At each temperature, $25^{\circ} \mathrm{C}, 30^{\circ} \mathrm{C}$ or $35^{\circ} \mathrm{C}, 10$ larvae were selected based on their orientation in the brood pile so that swallowing could be observed. Food was dyed green $(20 \%$ $\mathrm{v} / \mathrm{v})$ using across-the-counter food dye to increase the visibility of the bolus. Bolus size does not change with growth in 4th instar (Cassill and Tschinkel, 1996).

Temperature did not affect the rate of larval swallowing $(2.2 \pm 0.2 / \mathrm{s}$, mean \pm S.E.M.; $P=0.914)$ or the duration of larval swallowing (11.8 \pm 1.9 s, mean \pm S.E.M.; $P=0.691)$. Larvae stopped swallowing after $\sim 12 \mathrm{~s}$ regardless of how long workers offered food to them. The drop in the duration of larval swallowing after $\sim 10$ $12 \mathrm{~s}$ was also observed in hand-fed larvae (Cassill and Tschinkel, 1996). All together, these findings demonstrated that meal size in larvae was unaffected by incubation temperature.

\subsection{Worker brood tending}

Worker coverage of the brood pile was inversely proportional to temperature, decreasing about $30 \%$ as temperature increased from $25^{\circ} \mathrm{C}$ to $35^{\circ} \mathrm{C}(P<0.003$; Fig. 1a). Despite the decrease in the number of workers tending brood, the rate of larval encounter by workers increased almost two-fold with temperature $(P<0.001$; Fig. 1b). To attain this increase in larval contact with fewer workers, the tempo of workers had to increase three-fold over the range of temperatures from $25^{\circ} \mathrm{C}$ to $35^{\circ} \mathrm{C}-$ a $30 \%$ increase in worker tempo per degree increase in temperature.
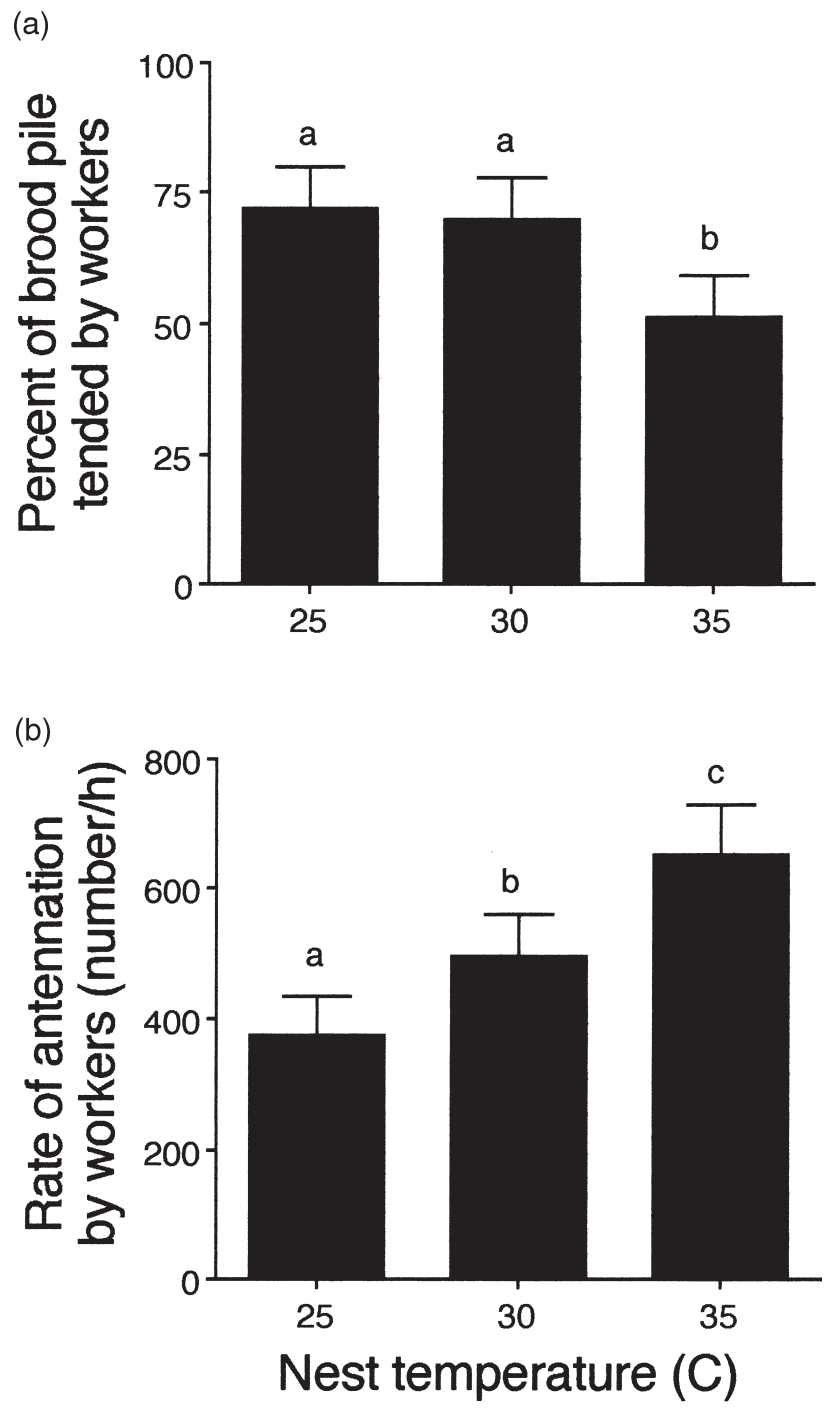

Fig. 1. Worker brood-tending behavior versus temperature. (a) Percent of workers tending larvae per unit of brood pile was inversely related to temperature. (b) In contrast, the rate at which workers encountered larvae (number/h) increased proportionately with temperature. The end result was that brood tending was unaffected by incubation temperature. Mean \pm S.E.M.

\subsection{Worker recruitment}

The pattern of recruitment varied significantly with time $(P<0.0001$; Fig. 2$)$, and there was a significant interaction between variables $(P<0.001)$. Initially, the number of workers recruited to food at $35^{\circ} \mathrm{C}$ was twice the number of those recruited at $25^{\circ} \mathrm{C}$. After $60 \mathrm{~min}$, the reverse was true. Thus, nearly the same total number of workers was recruited to the food site regardless of temperature $(P=0.212)$.

\subsection{Humidity}

Four hours after food introduction, all larvae housed in moist chambers (100\% humidity) were fed while none 


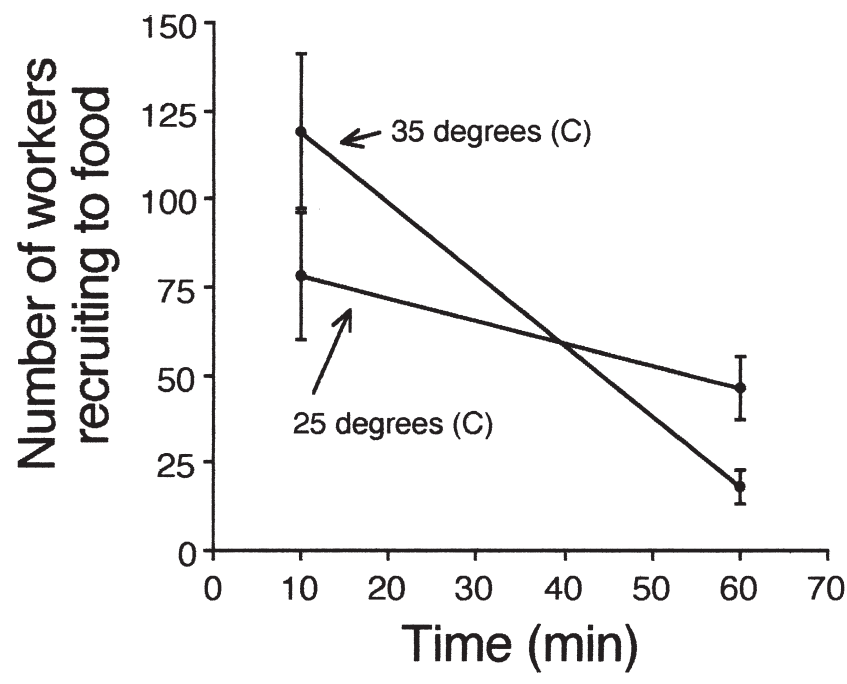

Fig. 2. Workers recruitment to food versus temperature. When ambient temperature was $35^{\circ} \mathrm{C}$, the initial rate of recruitment was high, but declined quickly. In contrast, when ambient temperature was $25^{\circ} \mathrm{C}$, the initial rate of recruitment was low but continued at that level for an extended period. In the end, the same total number of workers was recruited to the food site regardless of temperature.

housed in dry chambers ( $\sim 50-65 \%$ humidity) was fed. Larvae were far more densely piled in dry chambers, taking up about one-half the surface area of those in dampened chambers. Over the next two weeks, regardless of nest moisture, workers recruited to food, shared food with other workers via regurgitation, and groomed larvae (presence/absence of these behaviors was recorded). However, even in the presence of abundant food, larvae in the dry chambers starved to death and eventually were cannibalized.

\section{Discussion}

Contrary to the predictions of the von Bertalanffy rule (1960), neither worker body size nor larval meal size was affected by incubation temperature. Homeostasis in the development of worker-biased larvae and in their meal size was achieved by a combination of compensatory development and behaviors. Additionally, sexuals, which are far larger in body size than workers, were reared only at high rather than the low incubation temperature. A discussion of the compensatory mechanisms regulating the homeostatic development and behavior of worker-biased larvae follows.

\subsection{Developmental homeostasis}

Although temperature can extend the duration of larval development two-fold (Porter, 1988; Porter and Tschinkel, 1993), little is known of its effect on the rate of larval growth. There are two possible relationships between temperature and growth rate, either of which can be inferred from the size of workers at eclosion. If larval growth rate is temperature-independent, then temperature-delayed development in a cool incubation chamber should result in a larger pupa. This hypothesis is consistent with the von Bertalanffy rule (1960). However, if larval growth rate is temperature-dependent, then larvae will pupate at the same size regardless of incubation temperature. We found that worker-biased larvae pupated at the same mean size regardless of incubation temperature. Thus, developmental homeostasis is achieved by a temperature-dependent growth rate as well as a temperature-dependent developmental duration. Both changed similarly with temperature.

Worker size is an important factor in division of labor (Cassill and Tschinkel, 1999c) and worker longevity (Calabi and Porter, 1989) in the fire ant. Therefore, a stable mean and a stable variation in worker body size may be an adaptation by this perennial species to cope with diurnal and seasonal fluctuations in temperature. In support of this speculation is the fact that mean worker size does not vary within or among seasons in mature fire ant colonies (unpublished data).

The fire ant was an exception to the von Bertalanffy rule in a second way. Sexuals (males and gynes), which are far larger than workers, were produced at high rather than low incubation temperature. The presence of males in one but not the other treatment suggests that workers cannibalized sexual larvae at the low temperature. Both of our findings, temperature dependent sexual production and temperature independent worker body size, were consistent with another ant species, Myrmica (Elmes and Wardlaw, 1983). Because we did not test the effects of temperature on eggs or early instar larvae, we can not rule out the possibility that worker body size is temperature sensitive, if exposure occurs at an earlier developmental stage. Until additional experiments are completed, the issues of whether caste determination and body size are regulated by the same or different mechanisms, and whether these mechanisms include a temperature switch (Brian, 1956, 1973), a nutritional switch (Wheeler, 1986, 1990) or both (Passera, 1974), remain unanswered.

\subsection{Behavioral homeostasis}

Despite a $10^{\circ} \mathrm{C}$ difference in the temperature within brood chambers, larvae received the same total volume of food. Meal size homeostasis was achieved through several compensatory mechanisms. First, although temperature extended the duration of each worker-to-larva regurgitation event, the rate and duration of larval swallowing was unaffected. Thus, larvae ingested the same volume of food regardless of how long a worker presented it to them. Second, worker number and worker tempo varied with temperature in such a way that the rate of brood tending by workers was homeostatic. 
Third, colonies achieved recruitment homeostasis by increasing the initial rate of recruitment, but decreasing its duration at high temperature relative to low temperature (Fig. 2). The mechanism by which colonies modulate recruitment rate and duration at different temperatures is unknown.

\subsection{Humidity}

Although the effect of humidity on worker mortality is minimal (Hood and Tschinkel, 1990), its effect on larval mortality was dramatic. In dry nests, larvae were never fed even though workers were able to retrieve, sort, pile and groom them. The end result was that larvae died and were eventually cannibalized before they could pupate. We speculate that the mechanism by which larvae reduce their rate of desiccation is linked to their ability to signal for feedings.

In summary, our findings demonstrated that workerbiased larvae achieved developmental homeostasis in the face of variable incubation temperature through compensatory behaviors and development. Such homeostasis may be an adaptation by the fire ant to its perennial and weedy life style. Hogue and Hawkins (1991) found that temperature affected body size in species with a simple life-history pattern, but not in species with more complex life histories. Moreover, our results suggest that caste determination and body size may be regulated by entirely different genetic mechanisms or environmental triggers. In the final analysis, although much is known about the role of juvenile hormone in the timing of the developmental switch from one caste to another in ants (Wheeler, 1986, 1990, 1991, 1994), there remains much to be learned about the internal and external regulation of that switch.

\section{Acknowledgements}

We thank Michael Sloderbeck for programming the computerized event recorder "Timeant3" and Nick Daigle for transcribing video-taped feeding interactions. Additionally, we thank Diana Wheeler and two anonymous referees for critical reviews of the manuscript. This project was completed with support from the Center for Insect Science's National Institute of Health grant I-T32A107475 and the National Science Foundation grant IBN-9317853.

\section{References}

Arnett, A.E., Gotelli, N.J., 1999. Bergmann's rule in the ant lion Myrmeleon immaculatus DeGeer (Neuroptera: Myrmeleontidae): geographic variation in body size and heterozygosity. J. Biogeog. 26, 275-283.
Atkinson, D., 1994. Temperature and organism size — a biological law for ectotherms? Adv. Ecol. Res. 25, 1-58.

Atkinson, D., Sibly, R.M., 1997. Why are organisms usually bigger in colder environments? Making sense of a life history puzzle. Trends Evol. Ecol. 12, 235-239.

Banks, W.A., Lofgren, C.S., Jouvenez, D.P., Stringer, C.E., Bishop, P.M., Williams, D.F., Wojcik, D.P., Glancey, B.M., 1981. Techniques for rearing, collecting and handling imported fire ants. USDA and SEA Agriculture and Technology Southern Service 21, $1-9$.

Bouletreau-Merle, J., Sillans, D., 1996. Effects of interaction between temperature and $\mathrm{CO}_{2}$ on life-history traits of two Drosophila species (Diptera: Drosophilidae). Eur. J. Entomol. 93, 451-459.

Brian, M.V., 1955. Studies of caste differentiation in Myrmia rubra L. 3. Larval dormancy, winter size and vernalisation. Insectes Sociaux 2, 85-114.

Brian, M.V., 1956. Studies of caste differentiation in Myrmia rubra L. 4. Controlled larval nutrition. Insectes Sociaux 3, 369-394.

Brian, M.V., 1963. Studies of caste differentiation in Myrmica rubra L. 6. Factors influencing the course of female development in the early third instar. Insectes Sociaux 19, 91-102.

Brian, M.V., 1973. Temperature choice and its relevance to brood survival and caste determination in the ant Myrmica rubra L. Physiol. Zool. 46, 245-252.

Calabi, P., Porter, S.D., 1989. Worker longevity in the fire ant Solenopsis invicta: ergonomic considerations of correlations between temperature, size and metabolic rates. J. Insect Physiol. 35, 643649.

Cassill, D.L., 1996. Flow of food and social organization in the fire ant, Solenopsis invicta, The Florida State University, Tallahassee, Florida, p. 307.

Cassill, D.L., Tschinkel, W.R., 1995. Allocation of liquid food to larvae via trophallaxis in colonies of fire ants, Solenopsis invicta. Animal Behav. 50, 801-813.

Cassill, D.L., Tschinkel, W.R., 1996. A duration constant for workerlarva trophallaxis in ants. Insectes Sociaux 43, 149-166.

Cassill, D.L., Tschinkel, W.R., 1999a. Regulation of diet in the fire ant, Solenopsis invicta. J. Insect Behav. 12, 307-328.

Cassill, D.L., Tschinkel, W.R., 1999b. Effects of colony-level attributes on larval feeding in the fire ant, Solenopsis invicta. Insectes Sociaux 26, 261-266.

Cassill, D.L., Tschinkel, W.R., 1999c. Task selection by workers of the fire ant, Solenopsis invicta. Behav. Ecol. Sociobiol. 45, 301-310.

Elmes, G.W., Wardlaw, J.C., 1983. A comparison of the effect of temperature on the development of large hibernated larvae of four species of Myrmica (Hym Formicidae). Insectes Sociaux 30, $106-118$.

Gu, H., Danthanarayana, W., 1992. Influence of larval rearing conditions on the body size and flight capacity of epiphyas-postvittana moths. Aust. J. Zool. 40, 573-581.

Hogue, J.N., Hawkins, C.P., 1991. Developmental temperature and seasonal growth-patterns. J. North Am. Benthol. Soc. 10, 309-321.

Hood, W.G., Tschinkel, W.R., 1990. Desiccation resistance in arboreal and terrestrial ants. Physiol. Entomol. 15, 23-35.

Passera, P.L., 1974. Differenciation des soldats chez la fourmi Pheidole pallidula NYL, (Formicidae Myrmicinae). Insectes Socieaux 21, 71-86.

Porter, S.D., 1988. Impact of temperature on colony growth and developmental rates of the ant, Solenopsis invicta. J. Insect Physiol. 34, $1127-1133$.

Porter, S.D., Tschinkel, W.R., 1985. Fire ant polymophism (Hymentoptera: Formicidae): factors affecting worker size. Ann. Entomol. Soc. Am. 78, 381-386.

Porter, S.D., Tschinkel, W.R., 1986. Adaptive value of nanitic workers in newly founded red imported fire ant colonies (Hymenoptera: Formicidae). Ann. Entomol. Soc. Am. 79, 723-726.

Porter, S.D., Tschinkel, W.R., 1993. Fire ant thermal preferences: 
behavioral control of growth and metabolism. Behav. Ecol. Sociobiol. 32, 321-329.

Potts, L.R., Francke, O.F., Cokendolpher, J.C., 1984. Humidity preferences of four species of fire ants (Hymenoptera: Formicidae: Solenopsis). Insectes Sociaux 31, 335-339.

Richards, M.H., Packer, L., 1996. The socioecology of body size variation in the primitively eusocial sweat bee, Halictus ligatus (Hymenoptera: Halictidae). OIKOS 77, 68-76.

Slansky, F. Jr., Scriber, J.M., 1985. Food consumption and utilization. In:. Kerbut, G.A., Gilbert, L.A. (Eds.), Comprehensive Insect Physiology, Biochemistry and Pharmacology, vol. 14. Pergamon Press, Oxford, pp. 87-163.

Tschinkel, W.R., 1988. Colony growth and the ontogeny of worker polymorphism in the fire ant, Solenopsis invicta. Behav. Ecol. Sociobiol. 22, 103-115.

Tschinkel, W.R., 1998. The reproductive biology of fire ant societies. Biol. Sci. 48, 593-605. von Bertalanffy, L., 1960. Principles and theory of growth. In: Nowinski, W.N. (Ed.) Fundamental Aspects of Normal and Malignant Growth. Elsevier Press, Amsterdam, pp. 137-259.

Waller, D.A., La Fage, J.P., 1988. Environmental influence on soldier differentiation in Coptotermes formosanus shiraki (Rhinotermitidae). Insectes Sociaux 35, 144-152.

Wheeler, D.E., 1986. Developmental and physiological determinants of caste in social Hymenoptera: evolutionary implications. Am. Naturalist 128, 13-34.

Wheeler, D.E., 1990. The developmental basis of worker polymorphism in fire ants. J. Insect Physiol. 36, 315-322.

Wheeler, D.E., 1991. The developmental basis of worker caste polymorphism in ants. Am. Naturalist 138, 1218-1238.

Wheeler, D.E., 1994. Nourishment in ants: patterns in individuals and societies. In: Hunt, J., Nalepa, C.A. (Eds.) Nourishment and Evolution in Insect Societies. Westview Press, Boulder, Colorado, pp. 245-278. 